\title{
Safety Leadership and Human and Organisational Factors (HOF)-Where Do We Go from Here?
}

\author{
Kathryn J. Mearns
}

\begin{abstract}
Investigations into major disasters in safety critical industries consistently reveal failings in safety leadership, including poor decision-making and lack of effective challenge and inadequate management oversight and scrutiny of safety, as major contributory factors (e.g. Texas City, 2005; Royal Air Force Nimrod, 2006). More recently, a lack of regulatory oversight has also been implicated in disasters such as Deepwater Horizon [2] and Fukushima Daiichi [17]. There is also evidence of an inability to apply the lessons learned from major accidents, whether they have occurred in the same or other major accident hazard industries. This chapter considers these issues and the potential interplay between actors at the more senior levels of organisations and the regulators of the industries involved. The chapter also considers the role of safety culture assessments as a means of identifying the human and organisational factors that are either undermining or enhancing safety within the organisation and the need for senior leadership having the right mind-set to take due cognisance of this intelligence to implement measures that improve safety. Strong and competent regulators should support this approach.
\end{abstract}

Keywords Public inquiries $\cdot$ Leadership $\cdot$ Safety culture $\cdot$ Regulators

\begin{abstract}
The organizational causes of this disaster are deeply rooted in the histories and cultures of the offshore oil and gas industry and the governance provided by the associated public regulatory agencies. While this particular disaster involves a particular group of organizations, the roots of the disaster transcend this group of organizations. This disaster involves an international industry and its governance ([2], Investigation of the Macondo Well Blowout Disaster, p. 9).
\end{abstract}

K. J. Mearns ( $\square)$

Wood PLC, Aberdeen, UK

e-mail:k.j.mearns@gmail.com

(C) The Author(s) 2020

B. Journé et al. (eds.), Human and Organisational Factors,

SpringerBriefs in Safety Management,

https://doi.org/10.1007/978-3-030-25639-5_3 


\section{Introduction}

The quote given at the start of this chapter highlights the human, organisational, regulatory and 'cultural' shortcomings that have been consistently identified as underlying causes of major accidents in safety critical industries, irrespective of technology or regulatory regime. The list includes Bhopal, Herald of Free Enterprise, Three Mile Island, Chernobyl, Challenger, Columbia, Texas City, Royal Air Force (RAF) Nimrod, Deepwater Horizon and Fukushima Daiichi. The common failings identified from Public Inquiries and investigations into these major disasters, include:

- Ineffective leadership;

- Poor operational attitudes and behaviour;

- Poor decision-making and lack of effective challenge;

- Lack of training and competence;

- Inadequate management oversight and scrutiny of safety;

- Failure to apply safety lessons learned both from within and outside the organisation and/or industry.

The investigations invariably identify failings at the organisational level (i.e. senior leadership), particularly regarding decisions around the production/safety trade-off. For example, in his report into the loss of the RAF Nimrod, Charles Haddon-Cave [8], referred to 'A Failure of Culture, Leadership and Priorities' and provides damning criticism of Britain's largest defense and arms company:

The regrettable conduct of some of BAE Systems' managers ${ }^{1}$ suggests BAE Systems has failed to implement an adequate or effective culture, committed to safety and ethical conduct. The responsibility for this must lie with the leadership of the company (p. 261).

These investigations into major disasters also consistently call for 'lessons to be learned' but it would appear that either these lessons are quickly forgotten or there is a failure to implement the necessary actions arising from these lessons. For example, the Deepwater Horizon Study Group [2] reports that:

At the time of the Macondo blowout, BP's corporate culture remained one that was embedded in risk-taking and cost-cutting - it was like that in 2005 (Texas City), in 2006 (Alaska North Slope Spill), and in 2010 ("The Spill”), (p. 5).

BP clearly failed to implement the lessons learned from its previous disasters, as did NASA in the case of Challenger [25] and Columbia [24].

Apart from the major accident investigation findings, the research evidence shows strong support for the relationship between effective safety leadership at all management levels (including executives), a healthy safety culture and good safety performance (for reviews see [9, 10]). There is also an increasing focus on the role of regulators and their contribution to the aetiology of these disasters and a call for more competent and challenging regulators for the industries affected, i.e. offshore oil and gas (Deepwater Horizon) and nuclear industries (Fukushima Daiichi).

\footnotetext{
${ }^{1}$ BAE Systems is a British aerospace and defence large industrial group.
} 
The objective of this chapter is not to provide a new theory or share new ideas about how to improve human and organisational factors (HOF) in safety. On the contrary, the chapter explores the evidence that we already have to demonstrate that a focus on $\mathrm{HOF}$ is required to improve safety and how that focus can be achieved. As a result, this chapter covers three themes:

1. The role that leadership plays in developing and sustaining the safety culture of their organisations;

2. The importance of regular assessment of and attention to safety culture to identify the state of human and organisational factors that influence safety;

3. The role of a competent regulator in the oversight of leadership and management for safety and ensuring that adequate attention is paid to the findings of safety culture assessments to inform senior management leadership and decision-making.

\title{
2 The Role of Leadership in Developing and Sustaining Safety Culture
}

\begin{abstract}
Perhaps there is no clear-cut "evidence" that someone in BP or in the other organizations in the Macondo well project made a conscious decision to put costs before safety; nevertheless, that misses the point. It is the underlying "unconscious mind" that governs the actions of an organization and its personnel. Cultural influences that permeate an organization and an industry and manifest in actions that can either promote and nurture a high reliability organization with high reliability systems, or actions reflective of complacency, excessive risk-taking, and a loss of situational awareness [2, pp. 5-6].
\end{abstract}

A wealth of research data has been generated on how leadership at all levels of an organisation can influence the safety performance of front-line operations. This includes research on the role of supervisors [18, 27], middle management [15, 19] and senior management $[5,20]$. The role of senior management commitment to safety seems to be particularly important, in that their perceived attitudes, values and actions appear to be one of the most cited components of safety climate and safety culture research [4].

\section{The Role of Safety Climate and Safety Culture Assessments}

Senior managers set the agenda for safety in terms of their vision, values and strategy for safety, however this can only work if it is accepted, adopted and implemented throughout the whole organisation. Acquiring the right sort of 'safety intelligence' from the bottom up [7] is important. Managers at all levels of an organisation must 
be receptive to 'bad news' as well as 'good news' and they must be attentive to the 'signals' that indicate all is not well within their organisation and be willing to take action where necessary. A properly developed and implemented safety culture assessment provides a wealth of safety intelligence for managers to act upon.

Safety climate and culture assessments provide an opportunity for senior managers to gain an understanding of how the safety management systems (SMSs) and technical safety interventions as conceived and constructed are actually implemented in the organisation. There is often a mismatch between 'work as imagined' versus 'work as done' and between 'work as prescribed' versus 'work as disclosed' [3, 12]. Safety climate/culture assessments can assist in identifying where these mismatches lie and if properly conducted can identify the interventions that can close the gaps.

\section{The Role of the Regulator}

It is important for all employers and employees, to be aware of and fully understand, their duties under legal frameworks for health and safety. Within the UK this is enshrined in the Health and Safety at Work, etc. Act (1974) with other legislation arising from it, e.g. Management of Health and Safety at Work Regulations (1999).

More recently, the UK's Corporate Manslaughter and Homicide Act 2007, clarifies the criminal liabilities of companies where failures in the management of health and safety result in a fatality. Prosecutions are of the corporate body itself, however, directors, board members and others can still be prosecuted for separate health and safety offences. One of the challenges of the act is identifying 'the controlling mind', i.e. the person whose thoughts and actions control the company's affairs. This is particularly difficult in large companies where there are complex management structures and health and safety is often delegated to more junior managers who are not 'controlling minds'. Prosecutions therefore tend to be more successful under breaches of the Health and Safety at Work etc. Act 1974, although there have also been successful prosecutions under the Corporate Manslaughter and Homicide Act 2007 (e.g. the Lyme Bay tragedy).

Before an organisation ends up in court for serious breaches of health and safety legislation, government regulators have the power to shut down operations if they have evidence that the legislation is not being complied with. This is the sort of independent challenge that senior managers usually respect and pay attention to. It is the ultimate challenge, with severe consequences for the profitability of the organisation. If there is a fatality or major accident, the imposition of fines will hurt the company's 'bottom line'; the publicity and its consequences will hurt the company's 'reputation'. These are matters very close to any senior manager's heart. Furthermore, apart from the consequences for the organisation, there can also be consequences for the individual with many senior managers reporting they never want to be in a position to tell family members that a loved one will not be coming home following a fatal accident. Such experiences tend to develop managers who have a focus on health and safety. Fortunately, major accidents are comparatively 
rare events as are fatal accidents at work, so the capacity for this type of emotional learning is very limited and it could obviously never be endorsed.

In making decisions to shut down company operations, the regulator has to be 'proportionate' in its assessment with due reference to the concept of 'as low as reasonably practicable' (ALARP). This means that the regulator has to assess whether the measures taken are grossly disproportionate in relation to mitigating those risks. This trade-off has to be considered in the context of the law and what is acceptable from a risk management and safety perspective. ALARP serves society by placing a heavy weight on the precautionary principle in a way that controls risks for human beings and the environment. The practical procedures for implementing ALARP are mainly found in engineering judgements and codes but also in traditional cost-benefit analysis (CBA). According to Aven and Abrahamsen [1], CBA ignores uncertainties because it is based on attitudes to risk and uncertainty, which are 'risk neutral' and therefore in conflict with the precautionary principle and ALARP. French et al. [6] also identify shortcomings with CBA and advocate the implementation of multiattribute utility theory (MAUT) to address the perceptions of all stakeholder groups in order to facilitate constructive discussion. They argue that being explicitly subjective provides an open, auditable and clear analysis, which contrasts with the 'illusory' objectivity of CBA. The findings from safety climate/culture assessments reflect the perceived/subjective risks of stakeholders on the front-line and throughout the wider organisation and could be used in MAUT as another tool to add to the organisation's and the regulator's armoury to assess risks and support decision-making.

If senior management are so critical to developing and sustaining an organisation's safety culture and are instrumental in assessing and managing the organisation's health and safety risks, how can we determine whether they display the necessary leadership qualities, decision-making processes, capacity to manage organisational change and learn from previous accidents?

\section{A Regulatory Perspective on Leadership and Management for Safety (L\&MFS)}

The International Atomic Energy Agency (IAEA) has developed guidance for managers and regulators to assess L\&MfS [14]. The UK Office for Nuclear Regulation (ONR) provides an example of how this guidance has been implemented. The ONR regulates the UK nuclear industry using a set of Safety Assessment Principals (SAPs) that have to be complied with before nuclear organisations in the UK can be granted a licence to operate [16]. Four Management System (MS) SAPs are key: MS.1-Leadership; MS.2-Capable Organisation; MS.3 Decision Making and MS.4 Learning. Each SAP consists of a number of components, e.g. leadership attributes; control of organisational change; decision-making processes and learning culture, etc. These four ONR SAPs and their components also make clear links to safety culture. The ONR uses these SAPs and associated guidance to conduct L\&MfS reviews 
of duty holders as and when required. The managers of nuclear organisations have to demonstrate their competence in these areas as part of the Safety Case and Periodic Reviews of Safety (PRSs) to ensure that the company is still fit to operate.

Originally designed as a set of themes for discussions at the executive level of the organisation, the L\&MfS reviews allow the regulator to challenge senior managers on their leadership, their organisational capability, e.g. knowledge management and succession planning, decision-making, and learning ability, i.e. do they learn from incidents and implement the necessary changes to prevent such an incident occurring again. This can consist of a review of an organisation's safety management system (SMS) and a series of interviews and/or focus groups with a cross-section of the organisation's workforce, including senior management. Reviews of safety culture assessments, incident investigations and operating experience reports can also be conducted. These help to demonstrate the extent to which the 'work as imagined' matches 'work as done' and 'work as prescribed' matches the 'work as disclosed'.

Other regulators, e.g. the Health and Safety Executive [11] and industry bodies e.g. International Association of Oil and Gas Producers [13] have issued safety leadership guidance. Clear guidance and strong regulatory scrutiny can provide the necessary incentive for organisational leaders and senior managers to focus on improving their own decision-making processes and behaviour and appreciate the central role they play in developing and reinforcing the safety culture within the organisations they are responsible and accountable for.

\section{Conclusions}

Human, organisational, regulatory and 'cultural' shortcomings have been consistently identified as underlying causes of major accidents in safety critical industries, irrespective of technology or regulatory regime. Despite this wealth of data, there is also evidence of an inability to apply the lessons learned from major accidents, whether in the same or other industries. The challenges faced by the complex (and often complicated) organisations that run safety critical industries, should not be underestimated, however the evidence from public inquiries and investigations into major accidents indicate that demonstrations of stronger regulatory oversight and an engaged and accountable senior management are worthy of consideration. Furthermore, decades of research has shown that no matter what the industry, the same issues emerge from safety culture/climate assessments, i.e. perceived lack of senior management commitment to safety; inadequate communication (too much of the wrong sort or too little of the right sort); inadequate procedures (badly written or out-of-date); inability to 'speak up'/fear of 'challenging' about safety and lack of organisational learning.

On providing senior managers with feedback from their safety culture/climate surveys, there is often disbelief that the workforce views the organisation in this way. Indeed, a common finding from these surveys is that senior managers perceive the safety culture as much more positive than their workforces. As a result, there can be a 
reluctance to do anything about the findings. Action plans are developed but evidence of serious implementation is not necessarily forthcoming. Senior managers are very good at talking about the importance of safety but seem less able to address the human and organisational issues that undermine safety. They also often seem to be unable to implement the lessons learned from public inquiries into major accidents, despite the findings from these inquiries being widely available. What could be the reasons for this? Is it because interventions arising from safety culture/climate findings and the findings of public inquiries into major accidents are too costly? Or is there an attitude that this could never happen here? Or do senior managers simply not understand how HOF can influence the safety performance of an organisation? Given the decades of evidence to the contrary, these reasons are not tenable and yet, no other reasons come to mind except that making profits and keeping the shareholders happy are paramount and trump all other considerations. To some extent, this is understandable. Safety cannot be sustained if the company is not making money to invest in improvements. Fortunately, major accidents are rare events and therefore the attitude 'it cannot happen here', may be justified in the minds of senior managers, however, as Trevor Kletz is famously reported as saying, 'If you think safety is expensive, try having an accident'.

In order to make progress, safety critical industries require well-resourced and highly competent regulators who are capable of making strong and legitimate challenges to senior managers on their safety leadership qualities, backed up by enforcement action. Unfortunately, there has been a trend in recent years towards deregulation, often with drastic consequences, e.g. the 2008 financial crash, and continuing debates about whether or not the internet should be regulated. The lack of adequate regulation was also implicated in the Macondo (Deepwater Horizon) and Fukushima Daiichi disasters and a recent UK parliamentary inquiry into the collapse of the Carillion organisation, revealed evidence of weak financial and pensions regulators.

The way forward is for regulators and senior managers to work together to achieve safer and more resilient working environments in safety critical industries. However, we must not forget the workforce's involvement in this process and this is where safety climate and culture assessments play a role. These assessments provide good safety information to senior managers but only if properly developed and implemented by competent people with an understanding of the validity and reliability of their measures. Depending on the level of the analysis required, these assessments cover themes such as the lack of cross-communication, which prevents reciprocity, the validity of work systems and procedures, i.e. work as imagined and prescribed in the SMS does not reflect work as disclosed and done on the front-line, and the lack of leadership visibility to reinforce the norms and values that define the organisation. Leaders need to learn about and understand these issues by actively listening as well as observing because, as many public inquiries into major accidents have demonstrated, these are the conditions that could show that their organisation is drifting towards failure [3].

Woods [26] makes reference to the 4Is (independent, involved, informative and informed) and the need for an independent challenge of senior managers' decision 
making in their trade-offs between production and safety. Competent regulators can provide that independent and informed challenge along with the insights provided by properly developed and implemented safety culture/climate assessments, which ensures the involvement of the workforce in providing the information for management to act upon. These assessments can be used in the implementation of MAUT to address the perceptions of all stakeholder groups, facilitate constructive discussion and support the decision-making of senior managers and regulators.

\section{References}

1. T. Aven, E. Abrahamsen, On the use of cost-benefit analysis in ALARP processes. Int. J. Perform. Eng. 3(3), 345-353 (2007)

2. Deepwater Horizon Study Group, Final Report on the Investigation of the Macondo Well Blowout. Center for Catastrophic Risk Management, Mar 2011

3. S. Dekker, Malicious compliance, in Hindsight, Summer 2017, EUROCONTROL, vol. 25 (2017), pp. 8-9

4. R. Flin, K. Mearns, P. O'Connor, R. Bryden, Measuring safety climate: identifying the common features. Saf. Sci. 34(1-3), 177-192 (2000)

5. R. Flin, S. Yule, Leadership for safety: industrial experience. Br. Med. J. Qual. Saf. 13, 45-51 (2004)

6. S. French, T. Bedford, E. Atherton, Supporting ALARP decision-making by cost benefit analysis and multi attribute utility theory. J. Risk Res. 8(3), 207-233 (2005)

7. L.S. Fruhen, K. Mearns, R. Flin, B. Kirwan, Safety intelligence: an exploration of senior managers' characteristics. Appl. Ergon. 45, 967-975 (2014)

8. C. Haddon-Cave QC, The Nimrod Review. An Independent Review into the Broader Issues Surrounding the Loss of the RAF Nimrod MR2 Aircraft XV230 in Afghanistan in 2006 (The Stationary Office, London, 2009)

9. Health and Safety Executive, The role of managerial leadership in determining safety outcomes. Research Report 044, HM Stationary Office, Norwich (2003)

10. Health and Safety Executive, A Review of the Literature on Effective Leadership Behaviours for Safety. Research Report 952 (HSE Books, 2012)

11. Health and Safety Executive, Leading Health and Safety at Work, Actions for Directors, Board Members and Organizations of all Sizes. INDG 417 (HSE Books, 2013)

12. E. Hollnagel, Can we ever imagine how work is done?, in Hindsight, Summer 2017, EUROCONTROL, vol. 25 (2017), pp. 10-14

13. International Association of Oil and Gas Producers, Shaping safety culture through safety leadership. Report No. 452. London (2013)

14. International Atomic Energy Agency, Leadership and Management for Safety. General Safety Requirements, No. GSR Part 2, IAEA, Vienna (2016)

15. A. O'Dea, R. Flin, Site managers and safety leadership in the offshore oil and gas industry. Saf. Sci. 37, 39-57 (2001)

16. Office for Nuclear Regulation (ONR), Safety Assessment Principles, Version 0, (2014)

17. Organisation for Economic Co-operation and Development [OECD]/Nuclear Energy Agency (NEA), Five years after the Fukushima Daiichi Accident: Nuclear Safety Improvements and Lessons Learnt. NEA No. 7284, (OECD/NEA Publishing, 2 rue Andre-Pascal, 75775 Paris Cedex 16, 2016)

18. T.M. Probst, Organizational safety climate and supervisor enforcement: multilevel explorations of the causes of accident underreporting. J. Appl. Psychol. 100(6), 1899-1907 (2015)

19. Z. Rezvani, P. Hudson, Breaking the clay layer: the role of middle management in the management of safety. J. Loss Prev. Process Ind. 44, 241-246 (2016) 
20. I. Roger, R. Flin, K. Mearns, Safety leadership from the top: identifying the key behaviours, in Proceedings of the Human Factors and Ergonomics Society 55th Annual Meeting, Las Vegas, USA (2011)

21. UK Health and Safety Executive (HSE), Health and Safety at Work etc. Act 1974

22. UK Health and Safety Executive (HSE), Management Regulations, 1999

23. UK Ministry of Justice, Corporate Manslaughter and Corporate Homicide Act 2007

24. U.S. Columbia Accident Investigation Board (CAIB), Report of the Columbia Accident Investigation Board, Arlington, VA, vol. 1 (2003)

25. D. Vaughan, The Challenger Launch Decision: Risky Technology, Culture, and Deviance at NASA (University of Chicago Press, Chicago, 1996)

26. D. Woods, How to design a safety organization: test case for resilience engineering, in Resilience Engineering: Concepts and Precepts, ed. by E. Hollnagel, D. Woods, N. Levenson (CRC Press, Boca Raton, Florida, 2006)

27. D. Zohar, A group-level model of safety climate: testing the effect of group climate on microaccidents in manufacturing jobs. J. Appl. Psychol. 85, 587-596 (2000)

Open Access This chapter is licensed under the terms of the Creative Commons Attribution 4.0 International License (http://creativecommons.org/licenses/by/4.0/), which permits use, sharing, adaptation, distribution and reproduction in any medium or format, as long as you give appropriate credit to the original author(s) and the source, provide a link to the Creative Commons license and indicate if changes were made.

The images or other third party material in this chapter are included in the chapter's Creative Commons license, unless indicated otherwise in a credit line to the material. If material is not included in the chapter's Creative Commons license and your intended use is not permitted by statutory regulation or exceeds the permitted use, you will need to obtain permission directly from the copyright holder.

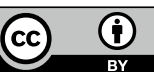

